\title{
Climate Response of Metasequoia glyptostroboides Inferred from Tree Rings, Secrest Arboretum, Wooster, Ohio, USA
}

\begin{abstract}
LAUREN J. VARGO, Antarctic Research Centre, Victoria University of Wellington, Wellington, New Zealand; GREGORY WILES ${ }^{1}$ and NICHOLAS WIESENBERG, Department of Earth Sciences, The College of Wooster, Wooster, OH, USA; CHRISTOPHER J. WILLIAMS, Department of Earth and Environment, Franklin \& Marshall College, Lancaster, PA, USA; and KEN COCHRAN, Ohio Agricultural Research and Development Center, The Ohio State University, Wooster, OH, USA.
\end{abstract}

ABSTRACT. Metasequoia glyptostroboides, a deciduous gymnosperm, also known as dawn redwood, was thought to be extinct until living members of the species were found in China in 1943. Analyzing the climate response of a transplanted stand of the trees can give insights into their physiological plasticity, into their use in restoration and reforestation, as well as into interpreting the environmental conditions of the geologic past from fossil Metasequoia. An annual ring-width chronology-spanning 1955 to 2010 and based on a stand of 19 M. glyptostroboides trees planted in Secrest Arboretum in northeast Ohio, USA-shows negative correlations with maximum monthly temperatures: with the strongest relationship with February and the warm months of June and July, all significant at the $99 \%$ confidence levels. A positive May to June precipitation correlation is the strongest moisture signal $(p<0.05)$ and the narrowest rings in the chronology occurred during the drought of 1987 to 1988, consistent with one of the warmest and driest Junes on record. These results have implications for the future as climate change affects the native and transplanted range of this species. Future response of this species to a changing climate will depend on the relative rates of warming maximum temperatures in the winter and summer, as well as changing moisture conditions during the summer months.

\section{INTRODUCTION}

Metasequoia glyptostroboides $\mathrm{Hu} \&$ W.C. Cheng, a deciduous gymnosperm also known as dawn redwood, was thought to be extinct until living trees were found in China in 1943 (Hu and Cheng 1948; Ma and Shao 2003). The fossil record of Metasequoia dates back to the Late Cretaceous, and the species is a common constituent of Cenozoic fossil floras and is widespread throughout the middle to high latitudes in the Northern Hemisphere (LePage et al. 2005). However, today's extant population is limited and may be the most restricted since the Miocene, perhaps linked to global aridity and cooling along with increased competition from Pinaceae (LePage et al. 2005).

Only about 5,400 individuals comprise the extant native population, which grows in the border region of Hunan, Hubei, and Sichuan provinces in south-central China. Native stands are scattered along moist ravines, ranging from approximately 800 to $1,500 \mathrm{~m}$ a.s.l., and are likely the remnants of more extensive stands that were lost due to human-induced land use change

${ }^{1}$ Address correspondence to Gregory Wiles, Scovel Hall, Department of Earth Sciences, The College of Wooster, Wooster, OH 44691, USA. Email: gwiles@wooster.edu
(Williams 2005; Tang et al. 2011). The species is listed as critically endangered in the International Union for Conservation of Nature's Red List of Threatened Species ${ }^{\mathrm{TM}}$ (Farjon 2013).

To prevent extinction of this relict species, extensive ex situ conservation efforts followed its discovery. Beginning in 1947, seeds were distributed worldwide. Today, the dawn redwood has been successfully cultivated in 50 different countries (Ma 2007). Despite the geographically restricted nature of the endemic population, $M$. glyptostroboides is capable of growing across a wide spectrum of climate conditions. Although it thrives in mesic temperate climates, it persists in North America from the humid continental climate of Montreal, Canada, to the subtropical, humid climate of New Orleans, Louisiana, USA (Williams 2005). $M$. glyptostroboides also grows quickly: stem length can grow over $30 \mathrm{~m}$ in less than 50 years (Williams 2005). The species puts on biomass rapidly, and therefore has the potential to be useful in carbon sequestration and soil stabilization efforts. 
Metasequoiaglyptostroboides has been well studied in terms of its paleobiogeography, ecophysiology, forest ecology, genetics, and horticultural properties (Kuser et al. 1997; Vann et al. 2004; LePage et al. 2005). Fossil wood has been studied to interpret pre-Quaternary paleoclimate (Kumagai et al. 1995; Jahren 2007; Richter et al. 2008). Finally, Holocene-age sub-fossil M. glyptostroboides, found within its native habitat, presents the opportunity for more recent paleoclimate studies (Yang et al. 2004).

Tree-ring studies of dawn redwood have been undertaken in Krakow, Poland (Wilczyński et al. 2014), where 18 planted trees, 40 years of age, were used in a ring-width series and correlated with local climate data as part of an analysis to assess the resistance of the species to urban pollution. No adverse effects were noted in the ring-width series with respect to air quality, but the climate analysis identified a negative relationship (strong growth with lower temperatures) with temperature for the coldest month of the year, January (significant at the 0.05 level). A significant negative relationship $(\mathrm{p}<0.05)$ was also identified with April and May temperatures. The precipitation signal in the Polish study was positive and strongest for the months of April and August and relative humidity was also positive for April to June (all significant at the 0.05 level). The negative correlation with temperatures in the spring and the positive correlations with precipitation and humidity in the spring and summer can be explained by high transpiration demands during these warm and dry months (Wilczyński et al. 2014).

Despite these previous studies of $M$. glyptostroboides, relatively little is known about their climatic response in North America; thus, further investigation of the climate-treering association in existing trees could prove informative for both paleoclimate reconstruction and assessing future forest health with respect to climate change. Better understanding of tree growth-climate association is also important because the native area of these trees is projected to warm by approximately $3{ }^{\circ} \mathrm{C}$ above the late20th-century baseline by the mid-21st century under RCP8.5 (Hijioka et al. 2014). This current report presents the first investigation of the climate response of $M$. glyptostroboides in North America by comparing ring-width series with mean monthly temperature data and total monthly precipitation data. This study sampled an ex situ collection that was established in 1953 at the Secrest Arboretum in Wooster, Ohio, USA.

\section{SITE DESCRIPTION AND METHODS}

Increment cores were collected from an original grove of $20 \mathrm{M}$. glyptostroboides trees, planted in 1953, at the Secrest Arboretum within the Ohio Agricultural Research and Development Center (OARDC) (lat $40^{\circ} 46^{\prime} 52^{\prime \prime N}$, long $81^{\circ} 54^{\prime} 57^{\prime \prime W}$; elevation: $311 \mathrm{~m}$ ), in Wooster, Ohio (Fig. 1A). Trees were planted in a grid of 4 rows approximately 3.5-meters apart. Monthly temperature and precipitation data spanning 1955 to 2010 were retrieved from the Global Historical Climatology Network (GHCN) (Peterson and Vose 1997). The weather data used was generated at a station located on the grounds of the Secrest Arboretum, about $0.3 \mathrm{~km}$ west of the sample site (Fig. 1A). The mean annual precipitation for the period of study was $950 \mathrm{~mm}$ with a mean annual temperature of $9.9^{\circ} \mathrm{C}$ (Fig. 1B). The growing season was generally from March to September, with the wettest months being May and June and the warmest being July and August. The coldest months were January and February, with February also being the driest month (Fig. 1B).

One to three cores were taken from each tree at breast height. Metasequoia glyptostroboides commonly form support buttresses at their base, which impacts the ring widths. Therefore, cores were collected avoiding the folds in the lower portion of the tree's buttresses. Samples were mounted and finely sanded in preparation for crossdating in The College of WoosterTree-Ring Laboratory. Cores were measured to the nearest $0.001 \mathrm{~mm}$ using a Velmex sliding stage micrometer. Annual increments were visually crossdated, as well as statistically crossdated using the computer program COFECHA (Holmes 1983). No missing rings were noted, although false rings were common (Fig. 2). While none of the series were truncated, some series with low correlations were eliminated from the climate analysis because, although they were correctly dated, they did not have a strong record of climate in their annual ring widths. The final chronology used 32 ring-width series from 19 different trees.

The chronology was standardized using the ARSTAN software, a freeware program developed at the Tree-Ring Lab of the Lamont-Doherty 


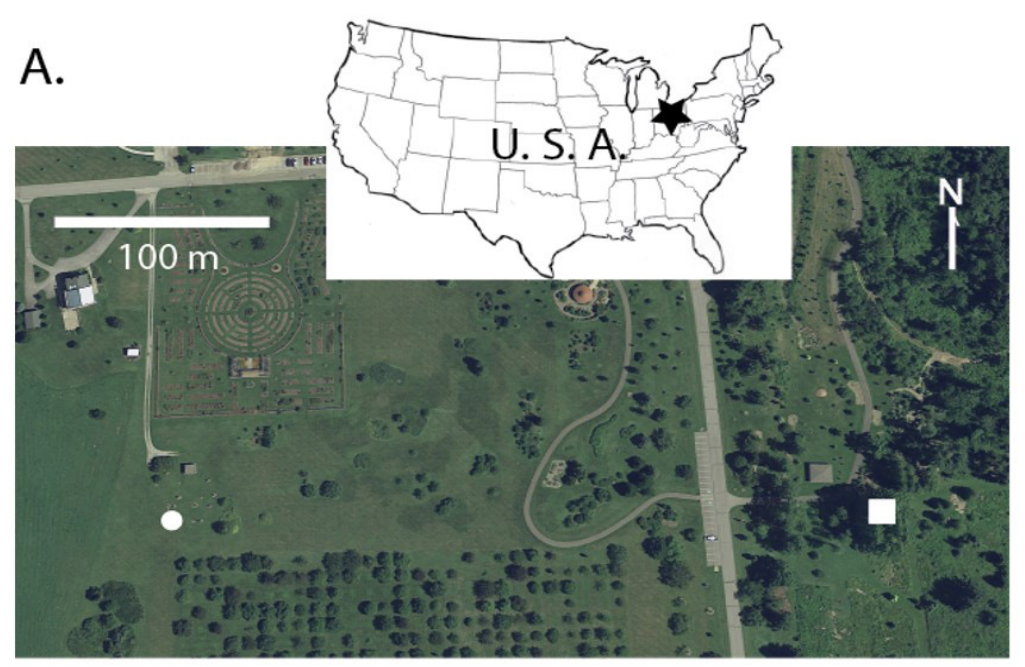

B.

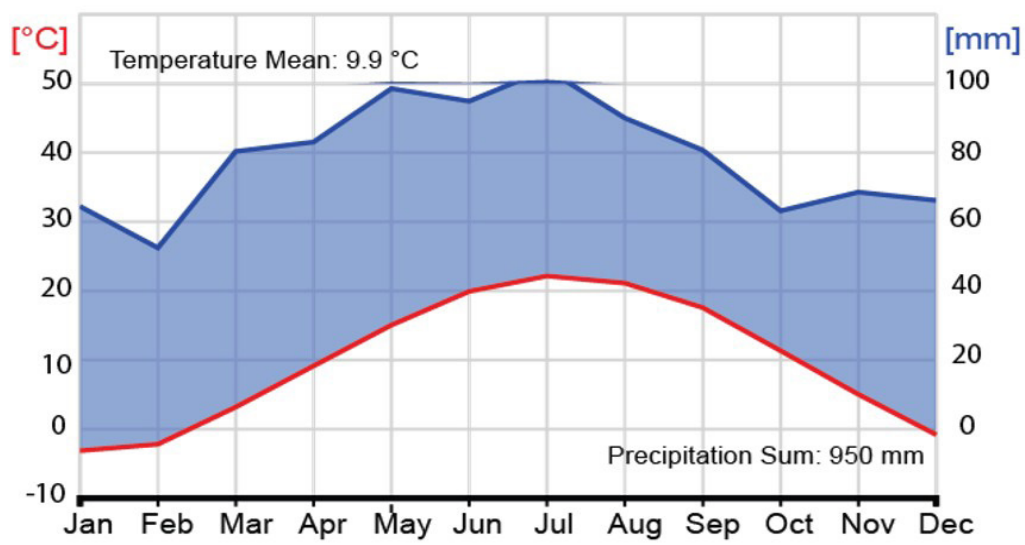

FIGURE 1. (A) Location map of the study site located within the Secrest Arboretum, Wooster, Ohio. Note that the meteorological station (white circle) on the campus of the OARDC is located approximately 300 meters west of the dawn redwood stand (white square). (B) Climograph showing the mean monthly temperatures (red) and precipitation (blue) for Wooster. February is the driest month of the year and the second coldest month.

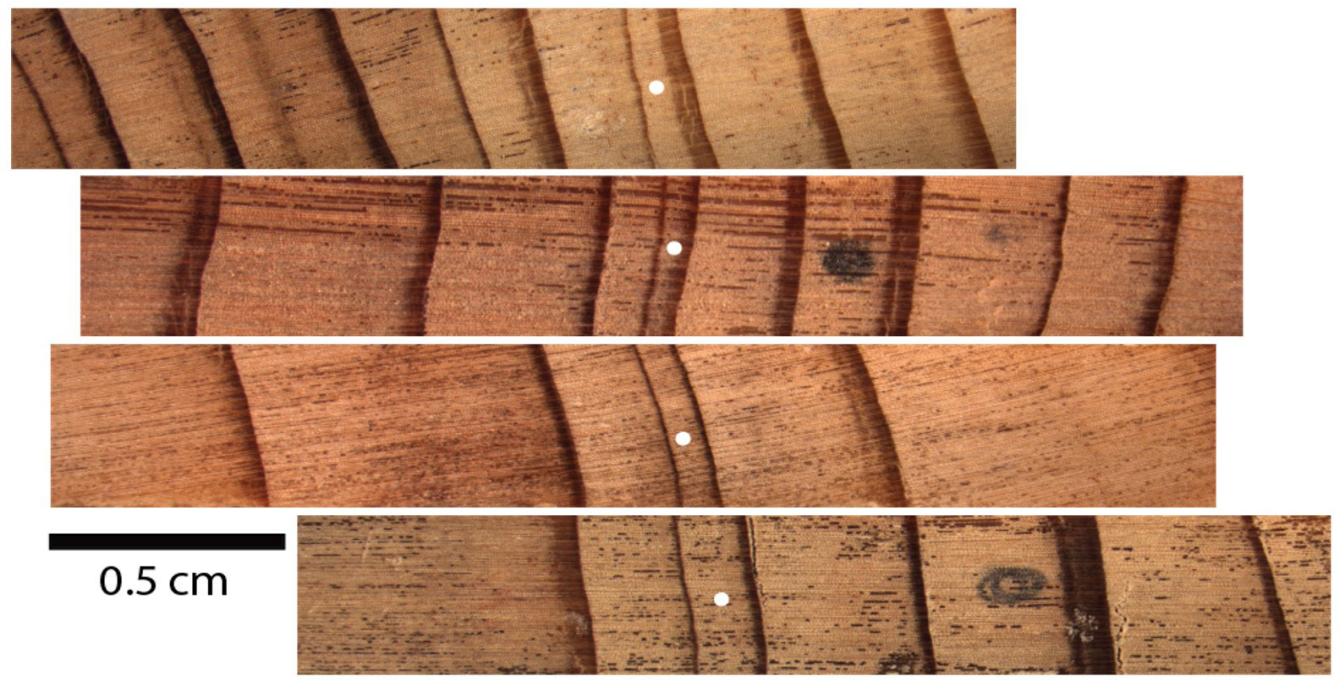

FIGURE 2. Four photomicrographs of dawn redwood cores. Growth is left to right and the white dot is placed on the earlywood of the 1988 ring. The 1987 to 1988 rings were the most-narrow of the series. Note that the upper core has some faint false rings that were common in some cores. 
Earth Observatory (https://www.ldeo.columbia. edu/tree-ring-laboratory/resources/software) based on the work of Cook (1985). Each raw series was conservatively detrended using either a negative exponential curve or a straight line through the mean. The negative exponential curve, which follows the expected growth function of a radially expanding tree, was used to detrend most series. This process produces a chronology of standardized ring-width indices that was then used in the climatic analyses. This study also generated a residual chronology using ARSTAN and examined this high frequency chronology for its climate signal.
The standard chronology (Fig. 3A) was then compared to the 51 years of mean, maximum, and minimum monthly temperature data and total monthly precipitation data spanning the period from 1960 to 2010. This study truncated the ringwidth series to begin at 1960 , when there were more than 10 cores in the chronology (Fig. 3A). Correlations for the 3 monthly temperature series and the total monthly precipitation were calculated for the dendroclimatic year (Speer 2012) (March through December of the previous year of growth and January through September of the year of growth) (Fig. 3B).
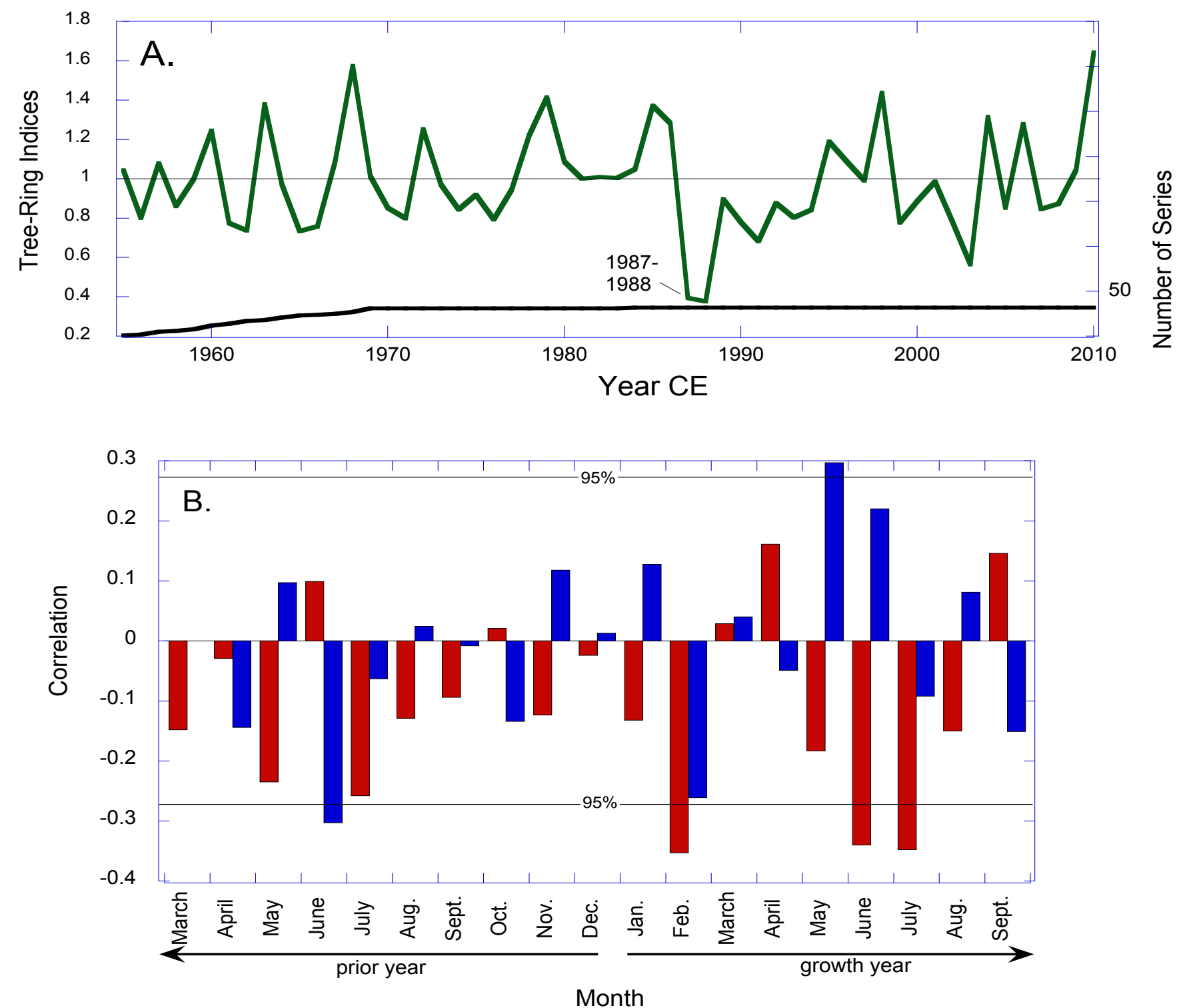

FIGURE 3. (A) The standard ring-width chronology developed using 32 series from 19 trees. The bold black line below the ring-width chronology indicates the number of series (sample size) through time. (B) Correlations of the maximum monthly temperature (red bars) and total monthly precipitation (blue bars) compared with the standard chronology for the dendroclimatic year (March through December of the previous year of growth and January through September of the year of growth). The $95 \%$ confidence levels are indicated. 


\section{RESULTS}

The final ring-width series for $M$. glyptostroboides has a mean sensitivity (a measure of year-to-year variability) of 0.38 , a mean series intercorrelation of 0.62 , and a mean first-order autocorrelation of 0.59 . The mean width measurement is $4.65 \mathrm{~mm}$, the mean segment length is 48 years, and the total chronology spans 56 years between 1955 and 2010 . Correlations of the standard chronology with both monthly precipitation and maximum temperature data (Fig. 3B) provide insight into the climatic controls on growth of $M$. glyptostroboides. The residual chronology yielded much weaker results than the standard chronology and thus the residual is not included here in the results; discussion below focuses on analyses of the standard chronology.

The trees exhibit a strong negative correlation with February maximum temperatures as well as June and July maximum temperatures for the growing season (Fig. 3B), all significant at the $95 \%$ confidence level or greater. For the month of February, the mean and minimum temperature series have stronger correlations than with the maximum temperatures (at -0.44 and -0.43 , for the mean and minimum temperatures; both highly significant $(\mathrm{p}<0.001)$ compared to the correlation of the maximum temperature series of -0.37 $(\mathrm{p}<0.008)$ Fig. 3B). The correlation for the average of June and July temperature values and ringwidths is $0.34(\mathrm{p}<0.02)$ and the first differenced correlation that emphasizes year-to-year variability is $0.36(\mathrm{p}<0.01)$. The May through June average precipitation series compared with ring widths correlates at $0.33(\mathrm{p}<0.02)$ and a correlation of the first differenced data for May to June precipitation is $0.43(\mathrm{p}<0.0002)$. The most-narrow rings are the years 1987 and 1988 (Fig. 2, Fig. 3A), which is a well-documented drought and warm period in northeast Ohio that persisted from September 1987 through August of 1988 (Rogers 1993).

\section{DISCUSSION}

The negative correlations with maximum June and July temperatures of the growth year (Fig. 3B) suggests that during warm summers tree growth is adversely affected, likely due to high evapotranspiration demands. Wet Mays and Junes have a positive relationship with tree growth consistent with higher amounts of summer moisture, which are favorable to tree growth during these warm months.
The negative correlations between $M$. glyptostroboides radial growth and maximum monthly February (the second coldest month in northeast Ohio) temperatures may be linked to the low snow cover. Cooler Februaries are favorable to tree growth. This relationship could be linked to more snow surviving into the spring and providing moisture to early growth. Additionally, the higher correlation with mean and minimum February temperatures than with maximum temperature is consistent with the possibility that snow pack in February may have a positive influence on tree growth-because cooler February temperatures and a surviving snowpack would protect this shallow-rooting species from frost damage in the root zone. The thermal protection of a snowpack against winter frost has been noted from the Midwest and at higher latitudes (e.g., Hennon et al. 2016; Buma et al. 2017; Reinmann et al. 2019).

A comparable climate response was found in the only other ring-width chronology assembled from dawn redwood, assessed near Krakow, Poland (Wilczyński et al. 2014). The Polish study similarly compared ring-width series to monthly climate records. The tree-ring series in the Polish study was built from 18 cores from 18 trees with a mean interseries correlation of $0.36(\mathrm{p}<0.05)$ spanning 1974 to 2011, a 37-year interval. The current study, which was 56 years in length (1955 to 2010) and included 32 cores from 19 trees, resulted in a series intercorrelation of 0.62 . The climate analysis for the dawn redwoods in Poland showed that for January (the coldest month in Krakow), May, and June, temperatures were negatively correlated with tree growth; the wet April and August months favored tree growth. Negative correlations with the warm months of April and May in Poland-and the similar finding in Ohio for the same months - indicate that warm summers and increased evapotranspiration can negatively impact tree growth. In the case of the Ohio trees, the reduced growth seen in the narrow marker years of 1987 to 1988 is consistent with this finding.

The negative winter temperature response for February in Ohio and January in Krakow is also consistent with tree growth benefitting from cooler winter months. The leading hypothesis put forth here to explain this observation is informed from work on Alaska cedar growth in the Pacific Northwest (Hennon et al. 2016; Buma et al. 2017) and in a variety of species from New Hampshire (Reinmann 
et al. 2019). These aforementioned studies show that warm winters can be detrimental to tree growth due to warmer temperatures leading to a loss of snowpack and subsequent root injury due to freezing. Furthermore, for the sites in the Pacific Northwest, climatic analyses using tree-rings are consistent with these findings (Wiles et al. 2012; Comeau et al. 2019; Wiles et al. 2019). Similar to the findings in Alaska, where mean winter temperatures at Alaska cedar sites are at a critical transition between 2 and $-2{ }^{\circ} \mathrm{C}$, the Wooster, Ohio, site falls within this zone as mapped by Buma et al. (2017). Buma et al. (2017) predicted that tree growth at locations within this critical temperature range would be susceptible to frost damage, especially as warming continues in many parts of the world. The northeast Ohio site is within this crucial winter temperature range and so is the Lichuan region of China, the present natural range of the M. glyptostroboides. The identification of this winter climate response may be useful to forest managers and arborists, because $M$. glyptostroboides continues to be listed as endangered (Farjon 2013). Further investigations, however, are needed to more fully explore the link between winter temperatures and tree growth.

\section{CONCLUSIONS}

The current tree-ring study from northeast Ohio is from a managed stand of $M$. glyptostroboides trees outside of their present native species range. These analyses, however, can yield insights about the future response of tree growth to changing climate in the natural region, as well as the potential of using M. glyptostroboides in climate reconstruction studies. This study shows that warming coupled with drying would adversely affect the growth of M. glyptostroboides. For Ohio, warming is coupled with increased moisture in the spring months and increased frequency of drought in the late growing season (USGCRP 2017); thus the health of the trees depends on the relative rates of these changes in northeast Ohio (Butler et al. 2015). For the winter season, the observed decrease in snowfall in the region (Butler et al. 2015) may be detrimental to tree growth whereas increased precipitation overall, in the form of summer rain, will benefit growth.

Future efforts should be directed towards better identifying the mechanisms that cause winter sensitivity in dawn redwood, thus refining the roles of summer precipitation changes relative to warming temperatures. These investigations would aid in the development of more robust climate and ecosystem models that incorporate drought stress and temperature thresholds in relation to tree health.

A final note acknowledges that this study, and the one in Krakow, Poland (Wilczyński et al. 2014), are both relatively short chronologies and from regions that are complacent with respect to climate response: the study trees of Wilczyński et al. (2014) are growing in a floodplain setting and the Ohio site in a managed arboretum. Tree-ring studies within the native range would better characterize the potential response of the dawn redwood growth within that native range. Given the remarkable rates of growth of dawn redwood, future tree-ring investigations could have implications in making decisions for tree plantings, carbon sequestration, and land preservation (Crowther et al. 2015).

\section{ACKNOWLEDGEMENTS}

The authors thank The College of Wooster Sophomore Research Program for support, and acknowledge the help of Sarah Appleton, Laura Monroe, Bill Hiatt, and Elizabeth Deering in field sampling. The tree-ring data from this study is archived at the International Tree-Ring Data Bank.

\section{LITERATURE CITED}

Buma B, Hennon PE, Harrington CA, Popkin JR, Krapek J, Lamb MS, Oakes LE, Saunders S, Zeglen S. 2017. Emerging climate-driven disturbance processes: widespread mortality associated with snow-to-rain transitions across $10^{\circ}$ of latitude and half the range of a climate-threatened conifer. Glob Change Biol. 23(7):2903-2914.

https://doi.org/10.1111/gcb.13555

Butler PR, Iverson L, Thompson FR, Brandt L, Handler S, Janowiak M, Shannon PD, Swanston C, Karriker K, Bartig J, Connolly S, et al. 2015. Central Appalachians forest ecosystem vulnerability assessment and synthesis: a report from the Central Appalachians Climate Change Response Framework project. Newtown Square (PA): United States Department of Agriculture, United States Forest Service, Northern Research Station. 310 p. General Technical Report NRS-146. https://doi.org/10.2737/NRS-GTR-146

Comeau VM, Daniels LD, Knochenmus G, Chavardès RD, Zeglen S. 2019. Tree-rings reveal accelerated yellow-cedar decline with changes to winter climate after 1980. Forests. 10(12): 1085 .

https://doi.org/10.3390/f10121085 
Cook ER. 1985. A time series analysis approach to tree ring standardization [doctoral dissertation]. [Tucson (AZ)]: University of Arizona. http://hdl.handle.net/10150/188110

Crowther TW, Glick HB, Covey KR, Bettigole C, Maynard DS, Thomas SM, Smith JR, Hintler G, Duguid MC, Amatulli G, et al. 2015. Mapping tree density at a global scale. Nature. 525:201-205.

https://doi.org/10.1038/nature14967

Farjon A. 2013. Metasequoia glyptostroboides. The IUCN Red List of Threatened Species 2013: e.T32317A2814244. [accessed 2019 October 23]. https://doi.org/10.2305/IUCN.UK.2013-1.RLTS.T32317A2814244.en Harris IC, Jones PD. 2017. CRU TS4.01: Climatic Research Unit (CRU) Time-Series (TS) version 4.01 of highresolution gridded data of month-by-month variation in climate (Jan. 1901-Dec. 2016). Centre for Environmental Data Analysis, 2017 December 04. University of East Anglia Climatic Research Unit. https://doi.org/10.5285/58a8802721c94c66ae45c3baa4d814d0

Hennon PE, McKenzie CM, D'Amore DV, Wittwer DT, Mulvey RL, Lamb MS, Biles FE, Cronn RC. 2016. A climate adaptation strategy for conservation and management of yellowcedar in Alaska. Portland (OR): United States Department of Agriculture, United States Forest Service, Pacific Northwest Research Station.382 p. General Technical Report PNW-GTR-917.

https://www.fs.fed.us/pnw/pubs/pnw_gtr917.pdf

Hijioka Y, Lin E, Pereira JJ, Corlett RT, Cui X, Insarov GE, Lasco R, Lindgren E, Surjan A. 2014. Asia (chapter 24). In: Barros VR, Field CB, Dokken DJ, Mastrandrea MD, Mach KJ, Bilir TE, Chatterjee M, Ebi KL, Estrada YO, Genova RC, et al., editors. AR5 Climate change 2014: impacts, adaptation, and vulnerability. Part B: regional aspects. Contribution of Working Group II to the fifth assessment report of the Intergovernmental Panel on Climate Change. Cambridge(UK) and New York (NY): Cambridge University Press. p. 1327-1370.

https://www.ipcc.ch/report/ar5/wg2/

Holmes RL. 1983. Computer-assisted quality control in treering dating and measurement. Tree Ring Bull. 43:69-78. http://hdl.handle.net/10150/261223

$\mathrm{Hu} \mathrm{HH}$, Cheng WC. 1948. On the new family Metasequoiaceae and on Metasequoia glyptostroboides, a living species of the genus Metasequoia found in Szechuan and Hupeh. Bul Fan Memorial Institute Biol. 1:153-161.

Jahren AH. 2007. The Arctic forest of the Middle Eocene. Annu Rev Earth Planet Sci. 35:509-540.

https://doi.org/10.1146/annurev.earth.35.031306.140125

Kumagai H, Sweda T, Hayashi K, Kojima S, Basinger JF, Shibuya M, Fukaoa Y. 1995. Growth-ring analysis of Early Tertiary conifer woods from the Canadian High Arctic and its paleoclimatic interpretation. Palaeogeogr Palaeocl. 116(3-4):247-262.

https://doi.org/10.1016/0031-0182(94)00100-M

Kuser JE, Sheely DL, Hendricks DR. 1997. Genetic variation in two ex situ collections of the rare Metasequoia glyptostroboides (Cupressaceae). Silvae Genetica. 46(5):258-264.
LePage BA, Yang H, Matsumoto M. 2005. The evolution and biogeographic history of Metasequoia. In: LePage BA, Williams CJ, Yang H, editors. The geobiology and ecology of Metasequoia. Topics in geobiology, vol 22. Dordrecht (NL): Springer. p. 3-114. https://doi.org/10.1007/1-4020-2764-8_1

Ma J. 2007. A worldwide survey of cultivated Metasequoia glyptostroboides Hu \& Cheng (Taxodiaceae: Cupressaceae) from 1947 to 2007. Bull Peabody Mus Nat Hist. 48(2):235253.

https://doi.org/10.3374/0079-032X(2007)48[235:AWSOCM]2.0.CO;2

Ma J, Shao G. 2003. Rediscovery of the first collection of the "living fossil", Metasequoia glyptostroboides. Taxon. 52(3):585-588.

https://doi.org/10.2307/3647458

Peterson TC, Vose RS. 1997. An overview of the global historical climatology network temperature database. Bul Am Meteorol Soc. 78(12):2837-2849.

https://doi.org/10.1175/1520-0477(1997)078<2837:AOOTGH>2.0.CO;2

Reinmann AB, Susser JR, Demaria EMC, Templer PH. 2019. Declines in northern forest tree growth following snowpack decline and soil freezing. Glob Change Biol. 25(2):420-430. https://doi.org/10.1111/gcb.14420

Richter SL, Johnson AH, Dranoff MM, LePage BA, Williams CJ. 2008. Oxygen isotope ratios in fossil wood cellulose: isotopic composition of Eocene- to Holocene-aged cellulose. Geochim Cosmochim Acta. 72(12):2744-2753. https://doi.org/10.1016/j.gca.2008.01.031

Rogers JC. 1993. Climatological aspects of drought in Ohio. Ohio J Sci. 93(3):51-59.

http://hdl.handle.net/1811/23559

Speer JH. 2012. Fundamentals of tree ring research. Tucson (AZ): University of Arizona Press. 368 p. ISBN-13: 978-0816526857.

Tang CQ, Yang Y, Ohsawa M, Momohara A, Hara M, Cheng S, Fan S. 2011. Population structure of relict Metasequoia glyptostroboides and its habitat fragmentation and degradation in south-central China. Biol Conserv. 144(1):279-289. https://doi.org/10.1016/j.biocon.2010.09.003

[USGCRP] United States Global Change Research Program. 2017. Climate science special report: fourth national climate assessment (NCA4), volume I. Wuebbles DJ, Fahey DW, Hibbard KA, Dokken DJ, Stewart BC, Maycock TK, editors. Washington (DC): United States Global Change Research Program. 470 p. https://doi.org/10.7930/J0J964J6

Vann DR, Williams CJ, LePage BA. 2004. Experimental evaluation of photosystem parameters and their role in the evolution of stand structure and deciduousness in response to palaeoclimate seasonality in Metasequoiaglyptostroboides $(\mathrm{Hu}$ et Cheng). In: Hemsley AR, Poole I, editors. The evolution of plant physiology. Amsterdam (NL): Elsevier-Academic Press. p. 428-444. Chapter 21. https://doi.org/10.1016/B978-012339552-8/50022-6 
Wilczyński S, Muter E, Wertz B. 2014. The application of the tree-ring chronologies in assessing ecological requirements of Metasequoia glyptostroboides growing in southern Poland. Geochronometria. 41(2):129-135. https://doi.org/10.2478/s13386-013-0149-y

Wiles GC, Charlton J, Wilson RJS, D’Arrigo RD, Buma B, Krapek J, Gaglioti BV, Wiesenberg N, Oelkers R. 2019. Yellow-cedar blue intensity tree-ring chronologies as records of climate in Juneau, Alaska, USA. Can J For Res. 49(12):1483-1492.

https://doi.org/10.1139/cjfr-2018-0525

Wiles GC, Mennett CR, Jarvis SK, D’Arrigo RD, Wiesenberg N, Lawson DE. 2012. Tree-ring investigations into changing climatic responses of yellow-cedar, Glacier Bay, Alaska. Can J For Res. 42(4):814-819.

https://doi.org/10.1139/x2012-028
Williams CJ. 2005. Ecological characteristics of Metasequoia glyptostroboides. In: LePage BA, Williams CJ, Yang H, editors. The geobiology and ecology of Metasequoia. Topics in geobiology, vol 22. Dordrecht (NL): Springer. p. 285-304. https://doi.org/10.1007/1-4020-2764-8_9

Yang JM, Yang XY, Liang H. 2004. The discovery of buried Metasequoia wood in Lichuan, Hubei, China, and its significance. Acta Palaeontologica Sinica. 43(1):124-131. In Chinese.

https://europepmc.org/article/CBA/358490 